Original Research Paper

\title{
The Effects of Using Crumb Rubber Modified Binder in an Asphalt Pavement
}

\author{
${ }^{1}$ Sayed Mohamad Soleimani*, ${ }^{1}$ Alanoud Faheiman and ${ }^{2}$ Zainab Mowaze \\ ${ }^{1}$ Department of Civil Engineering, Australian College of Kuwait, Kuwait \\ ${ }^{2}$ Civil Engineer, Kuwait Municipality, Kuwait
}

\author{
Article history \\ Received: 23-04-2020 \\ Revised: $12-05-2020$ \\ Accepted: 13-05-2020 \\ Corresponding Author: \\ Sayed Mohamad Soleimani \\ Department of Civil \\ Engineering, Australian \\ College of Kuwait, Kuwait \\ Email: s.soleimani@ack.edu.kw
}

\begin{abstract}
In this study, laboratory investigations have been carried out to characterize and demonstrate the improved performance of asphalt after modifying it with crumb rubber. The study has been divided into two main parts. Firstly, the physical characterizations of crumb rubber modified bitumen with different percentages of crumb rubber have been evaluated using penetration, softening point, viscosity, ductility and thin film oven tests. In the second part, Marshall Mix design has been performed for both asphalt rubber and control asphalt. After finding the optimum mix for both of them, Marshall and indirect tensile tests have been performed on both moisture-conditioned and -unconditioned cases to assess their performance in terms of stability, deformation, tensile strength and the effect of moisture on paving mixtures. Control asphalt samples have been prepared for the purpose of comparison. These laboratory investigations have been intended to evaluate utilizing crumb rubber in dense graded asphalt mixtures. Previous studies have shown that gap graded and dense graded asphalt rubber mixes performed better somehow than their respective conventional asphalt mixes. In addition, in Kuwait, gap graded mix is only used for chip seal while dense graded asphalt mix is used for main pavement layers such as wearing course and most of the pavement failures happen in this layer. The comparison between the experimental results of asphalt rubber and conventional asphalt showed that asphalt rubber is significantly better than conventional asphalt in terms of rutting and shear resistance as well as stability.
\end{abstract}

Keywords: Crumb Rubber Modified Binder, Dense Graded Asphalt Mixtures, Marshal, Rutting, Viscosity, Ductility

\section{Introduction}

Nowadays, numerous failures of pavements such as rutting and cracking have been prevalent in developing countries such as Kuwait (Arab Times, 2019). Rutting is a permanent deformation due to heavy traffic load and very high temperatures, while cracks are formed due to expansion and contraction caused by big volatile temperature changes between summer and winter. Also, due to poor drainage and heavy rainfall in winter, stripping and potholes are becoming increasingly prevalent in pavement. Stripping is the loss of bonds between aggregate and bitumen because of the poor adhesion between them (Moses et al., 2009).

Crumb rubber in the asphalt mixture causes a better fatigue life. Wang et al., (2013) reported that finer crumb rubber obtained a better fatigue life. Saberi et al. (2017) concluded that crumb rubber played a positive role in increasing the fatigue resistance. This is due to the fact that the fine size of crumb rubber can result in a homogeneous mixture and prevent any sedimentation in asphalt mixtures.

Several studies show improved performance of asphalt modified by crumb rubber, resulting in reduced cracking and increased fatigue life, strength, resilience, viscosity and adhesion (Hamzah et al., 2006; Kaloush, 2014; Kok and Kuloglu, 2007; Saberi. et al., 2017; Franesqui et al., 2019; Way et al., 2012).

Asphalt rubber binder is defined by the American Society of Testing Materials (ASTM) as "a blend of paving grade asphalt cements, ground recycled tire rubber and other additives as needed for use as binder in pavement construction in which the rubber component is at least $15 \%$ by weight of the total blend. The rubber shall be blended and interacted in the hot asphalt cement sufficiently to cause swelling of the 
rubber particles prior to use',

(ASTMD6114/D6114M-19, 2019).

In general, rubberized asphalt refers in large part to asphalt containing crumb rubber, though there is a slight difference between rubberized asphalt and asphalt rubber. The binder of rubberized asphalt may include less than $15 \%$ of crumb rubber as a modifier and thus may not comply with the ASTM definition of asphalt rubber (CDT, 2003). Throughout this paper, the term 'asphalt rubber' is used based on a composition consisting of $15 \%$ to $22 \%$ of rubber for crumb rubber modified bitumen and $17 \%$ of rubber for dense graded asphalt rubber mixtures.

\section{Literature Review}

Historically, the use of natural rubber in asphalt was patented in England in the early 1840s (Charles et al., 2000). In 1843, the process of modifying asphalt by using natural and synthetic rubber was introduced. In 1898, rubber was used for the first time as a modifier for asphalt binder. In 1950, the use of scrap tire as a modifier in asphalt was reported, due to its greater abundance and lower cost compared to natural rubber (Mashaan et al., 2014). In the 1960s, a materials engineer named Charles McDonald contributed to the development of a wet process for producing asphalt. Furthermore, he was the first to routinely use asphalt rubber in hot mix batching and surface treatment, such that he is now widely considered to be the primary catalyst in the emergence and popularity of asphalt rubber as a whole (CDT, 2003).

A large number of experimental studies have been conducted over the last several years with the aim of evaluating and improving the design philosophy, properties, specification and materials used in asphalt rubber (Kaloush, 2014; Saberi et al., 2017; Franesqui et al., 2019; Scofield, 1989).

By considering the life cycle costs for asphalt rubber paving materials, it is made apparent that asphalt rubber is a cost-effective alternative to many highway pavement applications. Many researchers have claimed that using rubberized bitumen increases the life expectancy of roads and improves the adhesion of aggregates, ultimately leading to better strength and stability (Hicks and Epps, 2018; Deshmukh and Kshirsagar, 2017).

In a comprehensive review done by The California Department of Transportation in 2014, the performance of rubberized asphalt over four decades of use led to the conclusion that pavement service life could be extended by using well-designed and properly manufactured asphalt rubber products. Reducing the content of bitumen in pavement construction also provides a noteworthy economical advantage. Moreover, this will lead to an efficient and reasonable use of wasted tire rubber, thus reducing environmental pollution (Zhou et al., 2014; Asadi et al., 2016).

Next to providing an economical advantage, the use of waste tire rubber in the construction of asphalt pavements affords structural advantages in relation to the properties of the pavement. Laboratory experiments showed that the addition of $10 \%$ tire rubber crumbs as a blending material in the bitumen improved the properties of the pavement (Arun and Ganesh, 2013). Furthermore, a DOT survey done in 2016 for the Oklahoma Department of Environmental Quality mentioned that as a result of using Ground Tire Rubber (GTR), performance was improved by providing better thermal cracking resistance, superior moisture-induced damage resistance, significant noise reduction, higher rut and crack resistance and better overall durability. It is mentioned in the same DOT survey that many agencies have used GTR in pavement because of its cost effectiveness and environmental benefits (Ghabchi et al., 2016).

Similarly, another study was conducted to determine the feasibility of using waste tires (crumb rubber) in the construction of asphalt pavements in Colorado. Two pilot test sections and one control section were constructed and observed. Pilot specification includes both the terminal blend and wet process to modify the asphalt binders. Also, a control section was constructed containing a conventional binder. The study established that the wet process pavement cost might be equal to the conventional pavement cost, since maintenance would not be required for the wet process pavement for about 10 years. In addition, the study demonstrated that the GTR pavements consumption energy is around 3,000 BTU/pound greater than the conventional asphalt pavement (Shuler, 2014).

Numerous studies have showed that CRM asphalt pavement has increased pavement performance (Tahmoressi, 2001; Mohammad et al., 2019; Said et al., 2015; Kaloush et al., 2010). Huang and his team presented a comparative study of laboratory and field performance of several applications of CRM hot-mix asphalt in Louisiana. After 5 to 7 years of traffic, the pavement sections constructed with CRM asphalt mixtures showed overall better performance in regards to rut depth and fatigue cracks than the corresponding control sections (Huang et al., 2002).

In regards to the effect of aggregate skeleton on mixture characteristic, several studies were conducted to understand the performance of the AR mixture with varying gradations including dense and gap graded (Way et al., 2012; Huang et al., 2002; Wang et al., 2013). Based on a state-of-the-art research review prepared by (Venudharan et al., 2016) many researches have used dense-graded gradation in order to investigate the enhanced performance. Most of the researchers found that rubber modification improved the performance comparing with conventional dense-graded.

In sum, it is evident that asphalt-rubber is relatively simple to make given the appropriate equipment and training. This has led to its widespread use in many countries, including but not limited to the USA, Portugal, Spain, Italy, Brazil, Russia, Sweden 
and China (Kaloush, 2014; Way et al., 2012; Venudharan et al., 2016).

\section{Objective}

Crumb rubber is an elastomeric material that can modify bitumen by increasing its resilience and viscosity, such that the performance of the asphalt mix is enhanced by virtue of improved adhesion between bitumen and aggregates.

Another serious problem-particularly in Kuwait-that may be resolved through the use of asphalt rubber is the considerable waste with respect to tires. Around seven million tires are in a disposal in Sulaibiya area in Kuwait and this can cause environmental catastrophe if fire erupts, leading to harmful gas emissions like similar to an event seen in a tire dump in Rhayyah in 2012. In total, around five million scrap tires have ignited and this underscores the importance of preventing such occurrences in the future (DMR, 2013).

The objective of this study is to find an ideal and hybrid solution for the two aforementioned problems. The proposed technique reduces the landfill disposal by utilizing waste tires as a modifier in bitumen, while simultaneously enhancing the performance of pavements.

\section{Materials and Methods}

\section{Materials}

The crumb rubber materials used in this study have been obtained from "Green Rubber Tire Recycling Plant", the only plant in Kuwait that produces crumb rubber from scrap and truck tires. Table 1 shows a comparison between the rubber gradation according to the sieve analysis of crumb rubber produced from the plant and the standard requirements based on Arizona Department of Transportation specification due to the fact that Kuwait and Arizona have similar climates (ADT, 2005). It shows that the rubber produced from the mentioned plant does not follow the requirements of both type A and type B. However, it was used in the laboratory experiments for this study because there is no other local source produces the crumb rubber in Kuwait.

In this study, the following binder tests have been performed on five samples of crumb rubber modified bitumen with different percentages of crumb rubber; $15 \%, 17 \%, 18 \%, 20 \%$ and $22 \%$, in addition to a control bitumen to evaluate their performance and identify the optimal mixture.

In the penetration test condition, a standard needle with a mass of $100 \mathrm{~g}$ is applied to the surface of the binder at $25^{\circ} \mathrm{C}$ temperature for $5 \mathrm{sec}$. The procedure used in this test is based on the American Society of Testing Materials standard (ASTM D5/D5M-13, 2013).

The softening point test was performed using a ring and ball apparatus, by suspending the ring containing the binder in water at $5^{\circ} \mathrm{C}$. Then, steel ball was placed on the binder sample and water was heated at a rate of $5^{\circ} \mathrm{C}$ per min. The temperature was recorded when the softened binder touched the apparatus plate (Mathew and Krishna Rao, 2006).

Figure 1 shows the conceptual relationship between temperature and asphalt viscosity. If the viscosity is higher than the required performance range, asphalt will be brittle and susceptible to low temperature cracking. Conversely, when the viscosity is below the range, it will flow readily, resulting in rutting which is considered as a permanent deformation (Michaeland John, 2011).

Direct Shear Reheometer is used to measure the rheological properties of modified and unmodified binders. The test has been conducted on both control and crumb rubber modified binders with different percentages of rubber to evaluate their performance in relation to viscosity by applying a range of shear stresses at elevated temperatures (Asphalt Academy, 2015).

In order to investigate the aging modes of distress namely fatigue cracking - on asphalt, a rolling thin film test was performed by using the thin film oven to measure the changes incurred in physical properties before and after heating. This test has been conducted on two samples; asphalt rubber binder with $17 \%$ and control bitumen by weighing about $50 \mathrm{~g}$ of each sample and heating to a temperature of $163^{\circ} \mathrm{C}$ for $5 \mathrm{~h}$ in a specified oven. The loss of weight after the heating period for each sample has been recorded.

The ductility test is performed by pulling the briquette mold containing the binder sample at a temperature of $25^{\circ} \mathrm{C}$ with a speed of $5 \mathrm{~cm} / \mathrm{min}$ (ASTMD113-17, 2017). It is considered that binders with very low ductility have poor adhesive properties and thus poor performance in service (Mang, 2003).

For safety purposes, the flash point test is performed by heating the binder in an open cup at a specified rate until the temperature at which a small flame passing over the surface of the cup causing vapours from the sample temporarily to flash or ignite (Mang, 2003). This test can detect the possible presence of highly volatile and flammable materials in asphalt.

\section{Marshall Mix Design}

\section{Aggregate Gradation}

In this study, the aggregate as shown in Table 2 was used to prepare dense graded mixes and all of them were limestone.

Aggregate particle size distribution was used to design the aggregate mix of both control and modified asphalt. This was achieved by performing sieve analysis for each aggregate size and then combining the results. In order to achieve the required aggregate gradation that follows specifications and is within the limits, trial and error method was used. 


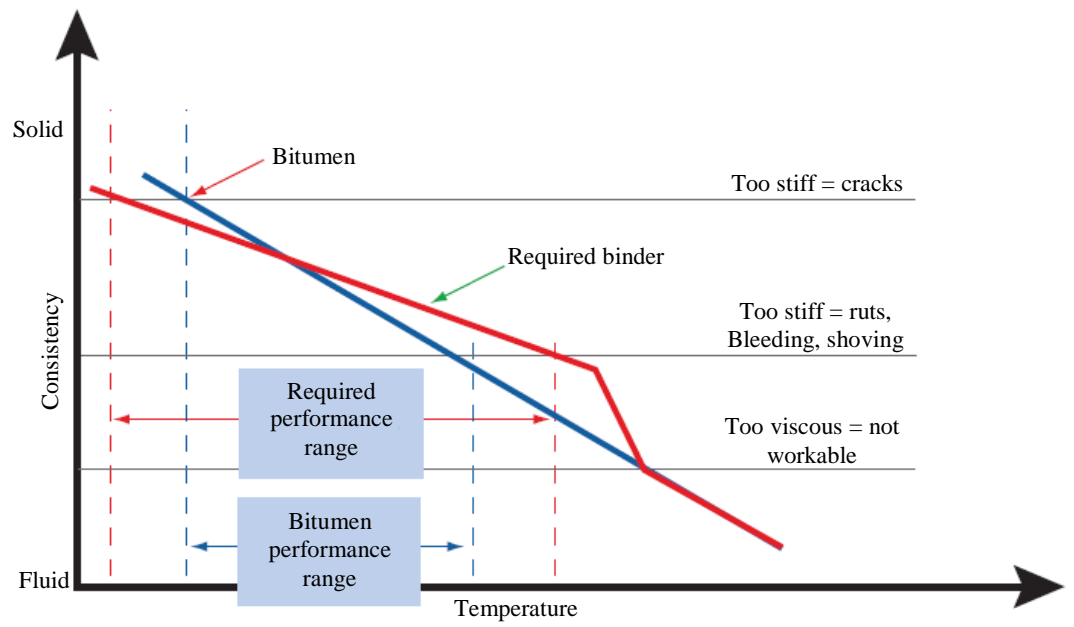

Fig. 1: Typical viscosity of a binder over temperature range (Asphalt Academy, 2007)

Table 1: Comparison of rubber gradation produced from plant and the standard requirements

\begin{tabular}{|c|c|c|c|}
\hline \multirow[b]{3}{*}{ Sieve Size $[\mathrm{mm}]$} & \multicolumn{3}{|c|}{ Percent Passing [\%] } \\
\hline & \multicolumn{2}{|c|}{ Standard Requirements ${ }^{\mathrm{a}}$} & \multirow{2}{*}{$\begin{array}{l}\text { Rubber gradation produced from } \\
\text { green rubber tire recycling plant }\end{array}$} \\
\hline & Type A & Type B & \\
\hline 2.360 & 100 & 100 & 99.0 \\
\hline 2.000 & $95-100$ & 100 & 91.8 \\
\hline 1.180 & $0-10$ & $65-100$ & 31.9 \\
\hline 0.600 & 0 & $20-100$ & 0.6 \\
\hline 0.300 & 0 & $0-45$ & 0.2 \\
\hline 0.075 & 0 & $0-5$ & 0.1 \\
\hline
\end{tabular}

a. (ADT, 2005)

Table 2: Mix design proportions - No.1 and No.2

\begin{tabular}{lll}
\hline & Mix design proportions (\%) & No.2 \\
Type used to prepare asphalt mix & No.1 & 25 \\
\hline Coarse aggregate $(19 \mathrm{~mm})$ & 20 & 35 \\
Coarse aggregate $(9.5 \mathrm{~mm})$ & 34 & 20 \\
Fine aggregate (Crushed Sand) & 23 & 16 \\
Fine aggregate (Natural Sand) & 19 & 4 \\
Mineral filler & 4 & Nable \\
\hline
\end{tabular}

Based on the Kuwaiti specification (MPW, 2012); “Coarse aggregate is that portion of the mineral aggregate retained on the No. 8 Sieve. Coarse aggregate shall consist of crushed natural stones and gravel. Crushed particles shall be cubic and angular in shape and shall not be thin flaky or elongated. The gradation shall be such that when combined with other aggregate fractions in proper proportions, the resultant mixture will meet the required gradation." The requirements are as follows:

- The fine aggregate shall not contain more than $20 \%$ natural sand by weight of total aggregate

- A minimum of $40 \%$ of the fine aggregate used in type III (wearing course) mixes shall be crushed sand

- The proportion of mineral filler used in any mix shall be not less than $3 \%$ nor greater than $5 \%$ by weight of the total aggregate
Two mix designs were used to determine the difference in their performances, as shown in Fig. 2 and 3.

\section{Preparation of Test Specimens}

In this study, the binder content ranges from $3.5 \%$ to $5.5 \%$ by total weight of the mix with $0.5 \%$ increments. The main steps of preparing Marshall specimens are as follows (ASTM D6926-16, 2016):

- Preparation of aggregates: Aggregates have been dried at $110^{\circ} \mathrm{C}$

- Preparation of Crumb Rubber Modified (CRM): Mixing of crumb rubber with hot bitumen at $180^{\circ} \mathrm{C}$ for one hour (ADT, 2005). According to the results of CRM binder testing, $17 \%$ of crumb rubber by total weight of binder has been chosen to be blended with bitumen 
- $\quad$ Preparation of mixtures: For each specimen test, the required amount of each aggregate and the binder to produce $1200 \mathrm{~g}$ have been mixed at $145^{\circ} \mathrm{C}$ thoroughly using a mechanical mixer

- Packing the mold: After mixing, each batch has been placed and spaded with heated trowel 15 times around the perimeter and ten times over the interior

- Compaction of specimens: The specimens have been compacted by applying 75 blows in each side of the specimens using compaction hammer. This number of blows has been chosen based on the design requirements for heavy traffic (Asphalt Institute, 1997), seeing as the Kuwaiti specification does not have provisions for this test and therefore
Manual Series no. 2 by the Asphalt Institute is used as an industry standard

\section{Mix Characteristics and Behaviour}

After preparing the compacted specimens, the volumetric properties have been determined to ensure that the mix meets specification criteria and give long term performance.

It is very important to limit the maximum levels of Voids in Mineral Aggregates (VMA) and subsequently maximum levels of binder content during the determination of optimum binder content.

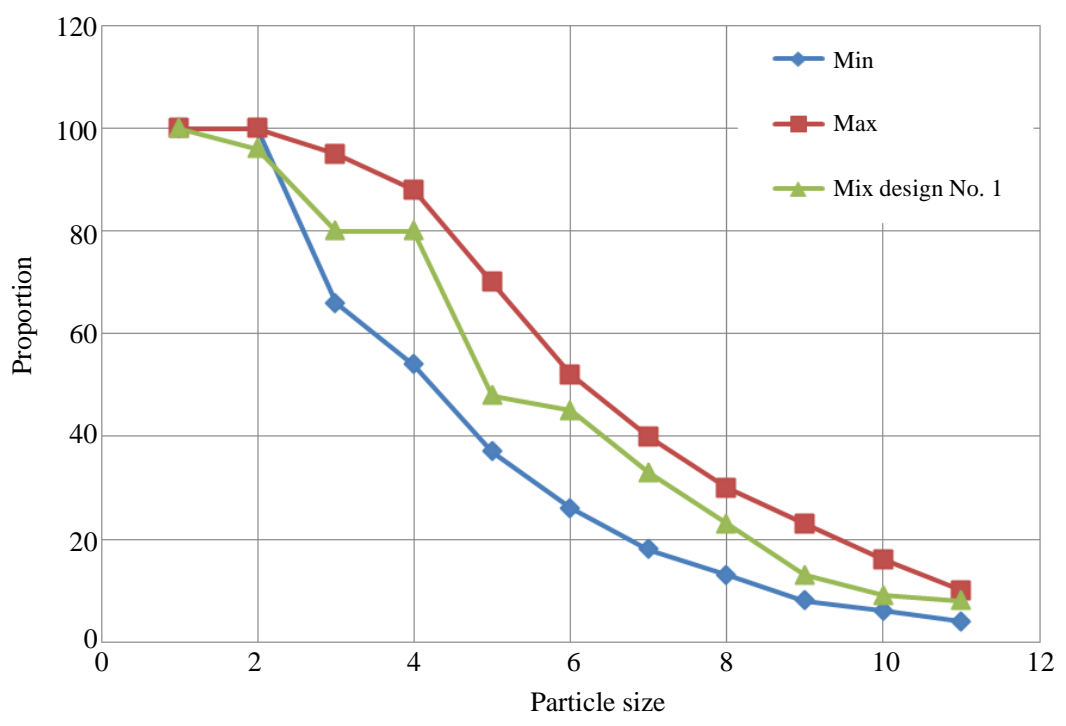

Fig. 2: Schematic graph of aggregate mix design-No. 1

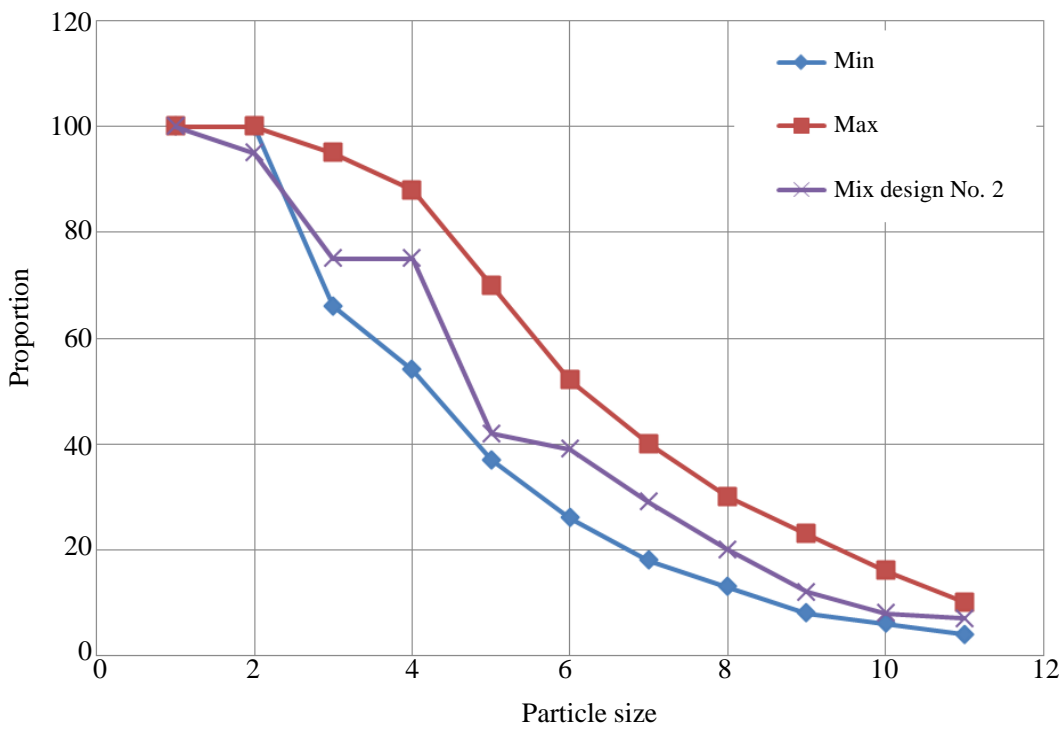

Fig. 3: Schematic graph of aggregate mix design - No. 2 


\section{Marshall Test}

The Marshall test is one of the most important tests for dense graded mixtures prepared by modified and unmodified bitumen. It was used in this study to measure the maximum load supported by compacted test specimens as well as the plastic flow as a result of loading. This test was performed on 15 specimens for both asphalt rubber and conventional asphalt to compare their capacity resistance to deformation as shown in Fig. 4.

\section{Binder Selection}

Based on the combined results of Marshall stability and flow and void analysis, optimum binder contents of both asphalt rubber and conventional asphalt have been determined by the following procedure:

- Separate graphs from the obtained results versus binder contents have been prepared

- Binder content corresponding to $4 \%$ air voids has been selected to be the optimum since it is the mean value of air voids range. In addition, it is mostly recommended in dense graded asphalt mix design

- Finally, the properties at this optimum binder content have been determined and compared against Marshall design specifications in order to check if the chosen mix is within the specifications or not

\section{Indirect Tensile Test (IDT)}

This test is considered one of the most common tests used for dense graded asphalt mixtures in evaluating the pavement structures in terms of resistance to fatigue and rutting. It is performed by loading a cylindrical specimen with compressive load acted parallel to and along the vertical diameter.

This compressive loading develops a relatively uniform tensile stress perpendicular to the direction of applied load which ultimately causes the specimen to fail by splitting along the vertical diameter. The specimen molds used to prepare Marshall samples were used to prepare samples for the IDT test. The indirect tensile strength was calculated using the following equation (Khosla and Harikrishnan, 2005; ASTM D6931-17, 2017):

$S_{t}=\frac{2000 P}{\pi t D}$

Where:

$S_{t}=$ Indirect tensile strength, $\mathrm{kPa}$

$P=$ Maximum load, $N$

$t=$ Specimen height before test, $\mathrm{mm}$

$D=$ Specimen diameter, $\mathrm{mm}$

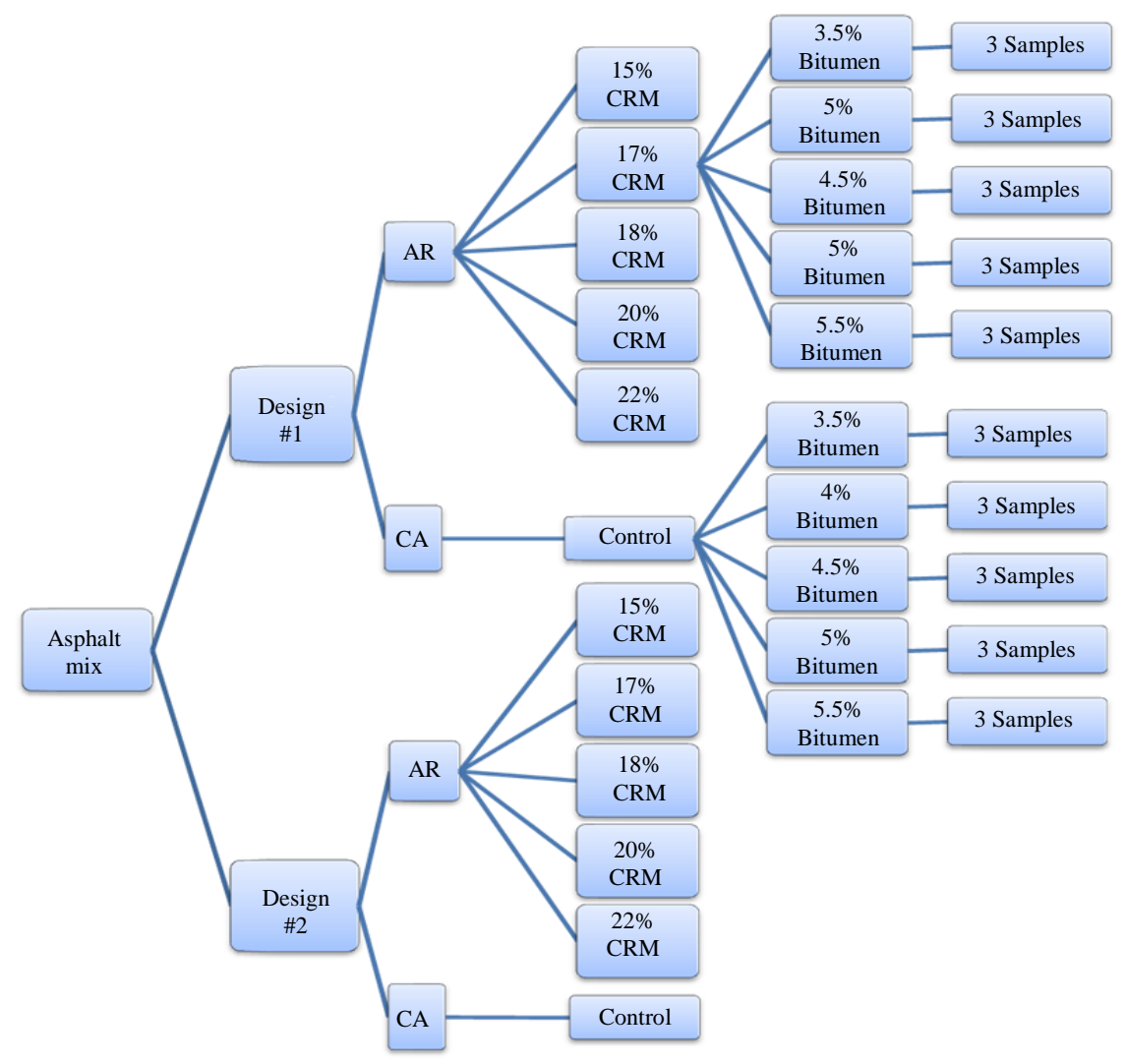

Fig. 4: Experimental testing matrix 


\section{Effect of Moisture on Paving Mixtures}

Moisture damage is one of the major problems that causes deterioration in asphalt pavement. It can be defined as the loss of strength and durability due to moisture exposure under loading (Emeny and Seddik, 1997). This distress plays significant role in other types of failures such as rutting, potholes and stripping. As a result, the bonds between aggregates and bitumen fail causing breaking down of the asphalt pavement.

This test method was used to evaluate the performance of asphalt rubber in terms of susceptibility to moisture damage. It was determined by preparing a set of compacted specimens divided into two subsets of approximately equal air voids. One subset was maintained dry while the other subset was immersed in water at $60^{\circ} \mathrm{C}$ for $24 \mathrm{~h}$. The potential for moisture damage has been indicated by the ratio of wet subset to dry subset (ASTM D4867/D4867M-09, 2009).

\section{Triaxial Test}

This test was performed in order to evaluate the shear resistance of asphalt rubber under various conditions of simultaneous axial and lateral loading. Since the specified apparatus of this test for asphalt mixtures was not available at our laboratories, the triaxial apparatus for soil was used. The basic procedure used in this test can be found in American Society for Testing Materials standard (ASTM D2850-15, 2015).

\section{Results and Discussion}

\section{Physical Characterization of Binders}

Table 3 shows the results of binder testing. Based on these results, the optimum percentage of crumb rubber as a modifier to the bitumen has been chosen. The chosen value was $17 \%$, since the binder with this percentage was found to meet all the physical requirements of asphalt rubber binder (Table 4) and showed significant enhancements compared to control bitumen (ASTM D6114/D6114M-19, 2019).

\section{Penetration Test}

Based on the results of this test, it has been noted that the penetration grade of asphalt rubber was significantly less than control bitumen. This means less deformation would be expected. Also, as the percentage of crumb rubber in asphalt rubber was increased, the penetration was decreased until it reached $22 \%$, the results became counterproductive. However, they are still within asphalt rubber binder requirements as described in the American Standard for Testing Materials standard (ASTM D6114/D6114M-19, 2019).

\section{Softening Point}

As the crumb rubber content was increased, the softening point was also increased. This means that CRM bitumen is less likely to show rutting and bleeding at high temperature since it is less susceptible to temperature. From this test, the result of CRM bitumen with $15 \%$ of rubber didn't meet the requirement so that $15 \%$ of crumb rubber was not chosen to produce asphalt rubber binder for this study. Consequently, $17 \%$ of crumb rubber was chosen because more than $17 \%$ is not recommended to be used for dense graded mixtures, as insufficient air voids cannot accommodate the swelling of crumb rubber.

\section{Viscosity Test}

The viscosity results of both CRM bitumen with different percentages of rubber and control bitumen (pure - neat binder) are presented in Fig. 5. According to these results, CRM bitumen had high values of viscosity and more than the control bitumen. As a result, the cohesion between aggregate particles would be increased.

Also, in pure (neat binder) the viscosity decreases by increasing the temperature (Fig. 5a). This is not the trend in CRM binders (Fig. 5b to 5f). This shows that the addition of crumb rubber is affecting the material behavior in different temperatures and further investigations are required to find an explanation for this phenomenon.

Table 3: Binder test results

\begin{tabular}{|c|c|c|c|c|c|c|}
\hline \multirow[b]{2}{*}{ Test } & \multirow[b]{2}{*}{ Control bitumen } & \multicolumn{5}{|c|}{ Rubber percentage in CRM bitumen } \\
\hline & & $15 \% \%$ & $17 \%$ & $18 \%$ & $20 \%$ & $22 \%$ \\
\hline $\begin{array}{l}\text { Penetration }(\mathrm{mm}) \text { at } 25^{\circ} \mathrm{C}, \\
100 \mathrm{~g}, 5 \mathrm{sec}\end{array}$ & 50 & 33 & 29 & 28 & 25 & 28 \\
\hline $\begin{array}{l}\text { Flash Point Cleveland } \\
\text { Open Cup }{ }^{\circ} \mathrm{C}\end{array}$ & $>232$ & $>235$ & $>239$ & $>240$ & $>243$ & $>251.5$ \\
\hline Softening Point ${ }^{\circ} \mathrm{C}$ & 50.6 & 55.4 & 68.0 & 62.7 & 70.8 & 74.1 \\
\hline Ductility at $25^{\circ} \mathrm{C}, 100 \mathrm{~g}, 5 \mathrm{sec}$ & 102.00 & 9.50 & 7.80 & 6.00 & 6.50 & 7.25 \\
\hline
\end{tabular}


Sayed Mohamad Soleimani et al. / American Journal of Engineering and Applied Sciences 2020, 13 (2): 237.253 DOI: 10.3844/ajeassp.2020.237.253

Table 4: Physical Requirements of Asphalt Rubber Binder (ASTM D6114 / D6114M-19, 2019)

\begin{tabular}{|c|c|c|c|c|}
\hline Binder Designation & & Type I & Type II & Type III \\
\hline Apparent Viscosity, $175^{\circ} \mathrm{C}\left[347^{\circ} \mathrm{F}\right]:$ & $\min$ & $1.5[1500]$ & $1.5[1500]$ & $1.5[1500]$ \\
\hline D4402/D4402M or D7741/ D7741M Pa.s & $\max$ & $5.0[5000]$ & $5.0[5000]$ & $5.0[5000]$ \\
\hline Penetration, $25^{\circ} \mathrm{C}\left[77^{\circ} \mathrm{F}\right] 100 \mathrm{~g}, 5 \mathrm{~s}:$ & $\min$ & 25 & 25 & 50 \\
\hline units (Test Method D5/D5M) & $\max$ & 75 & 75 & 100 \\
\hline $\begin{array}{l}\text { Penetration, } 4^{\circ} \mathrm{C}\left[39^{\circ} \mathrm{F}\right], 200 \mathrm{~g}, 60 \\
\text { s: Units (Test Method D5/ D5M) }\end{array}$ & $\min$ & 10 & 15 & 25 \\
\hline $\begin{array}{l}\text { Softening Point: }{ }^{\circ} \mathrm{C}\left[{ }^{\circ} \mathrm{F}\right] \\
\text { (Test Method D36/ D36M) }\end{array}$ & $\min$ & $57[135]$ & 54 [130] & $52[125]$ \\
\hline $\begin{array}{l}\text { Resilience, } 25^{\circ} \mathrm{C}\left[77^{\circ} \mathrm{F}\right]: \% \\
\text { (Test Method D5329) }\end{array}$ & $\min$ & 25 & 20 & 10 \\
\hline Flash Point: ${ }^{\circ} \mathrm{C}\left[{ }^{\circ} \mathrm{F}\right]$ (Test Method D92) & $\min$ & $232[450]$ & $232[450]$ & $232[450]$ \\
\hline $\begin{array}{l}\text { Thin-Film Oven Test Residue } \\
\text { (Test Method D1754/ D1754M) }\end{array}$ & $\cdots$ & $\ldots$ & $\ldots$ & $\ldots$ \\
\hline $\begin{array}{l}\text { Penetration Retention, } 4^{\circ} \mathrm{C}\left[39.2^{\circ} \mathrm{F}\right] \text { : } \\
\% \text { of original (Test Method D5/ D5M) }\end{array}$ & $\min$ & 75 & 75 & 75 \\
\hline
\end{tabular}

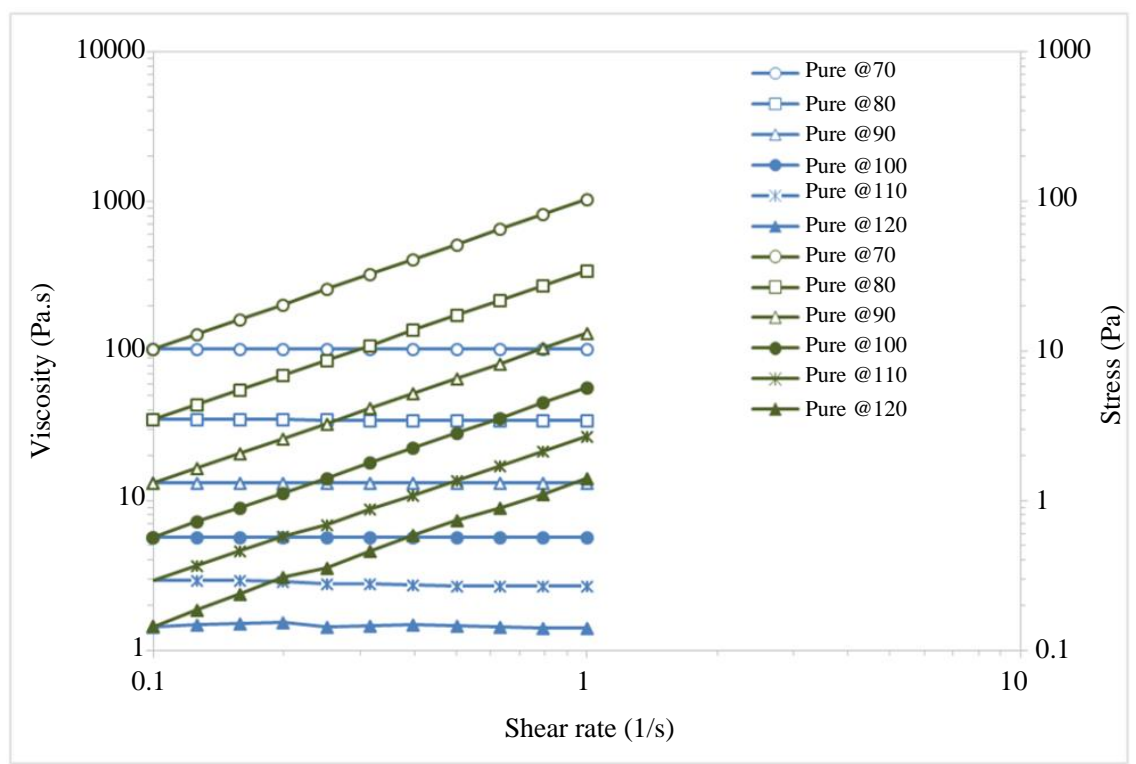

(a)

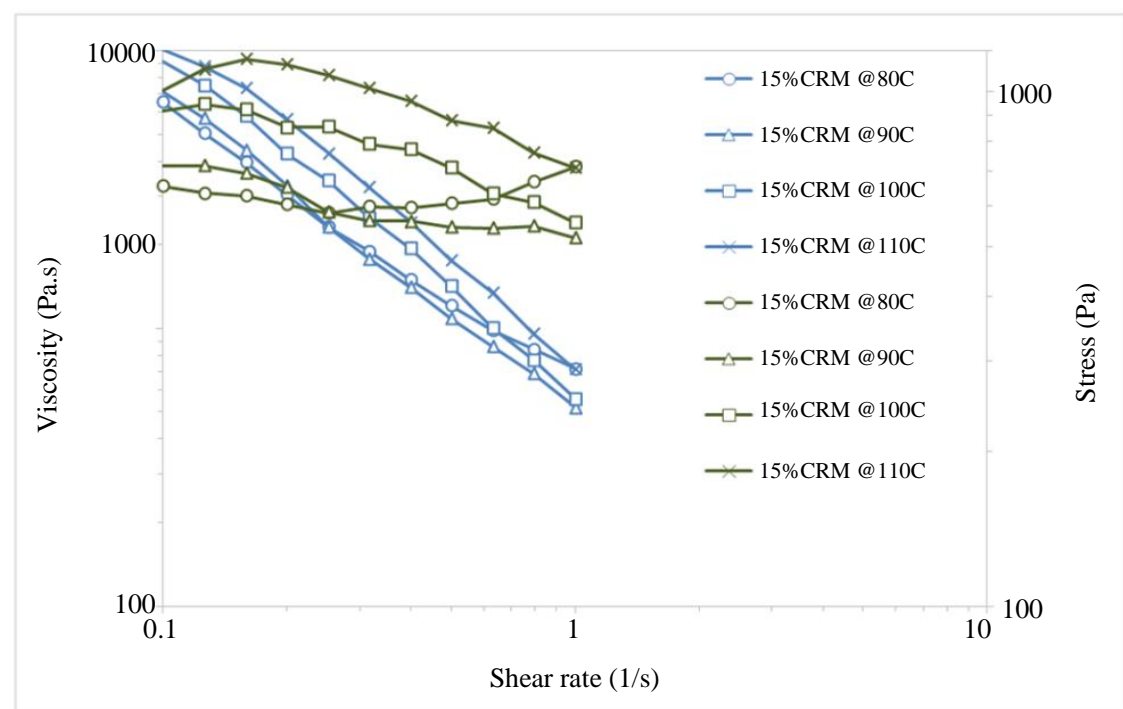

(b) 
Sayed Mohamad Soleimani et al. / American Journal of Engineering and Applied Sciences 2020, 13 (2): 237.253 DOI: 10.3844/ajeassp.2020.237.253

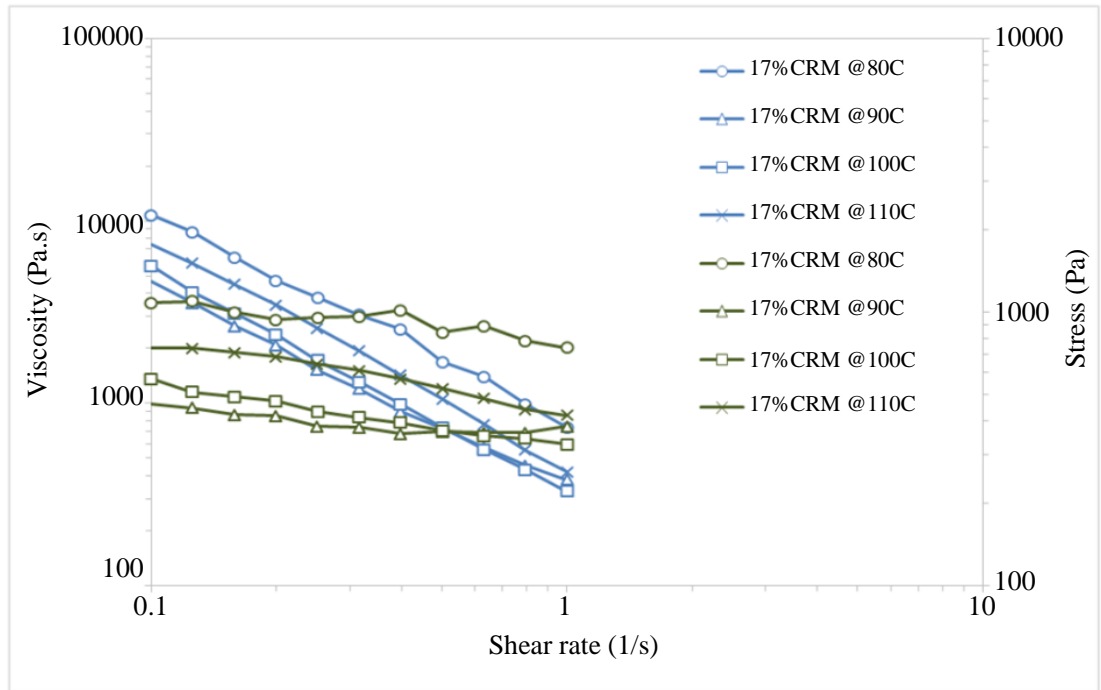

(c)

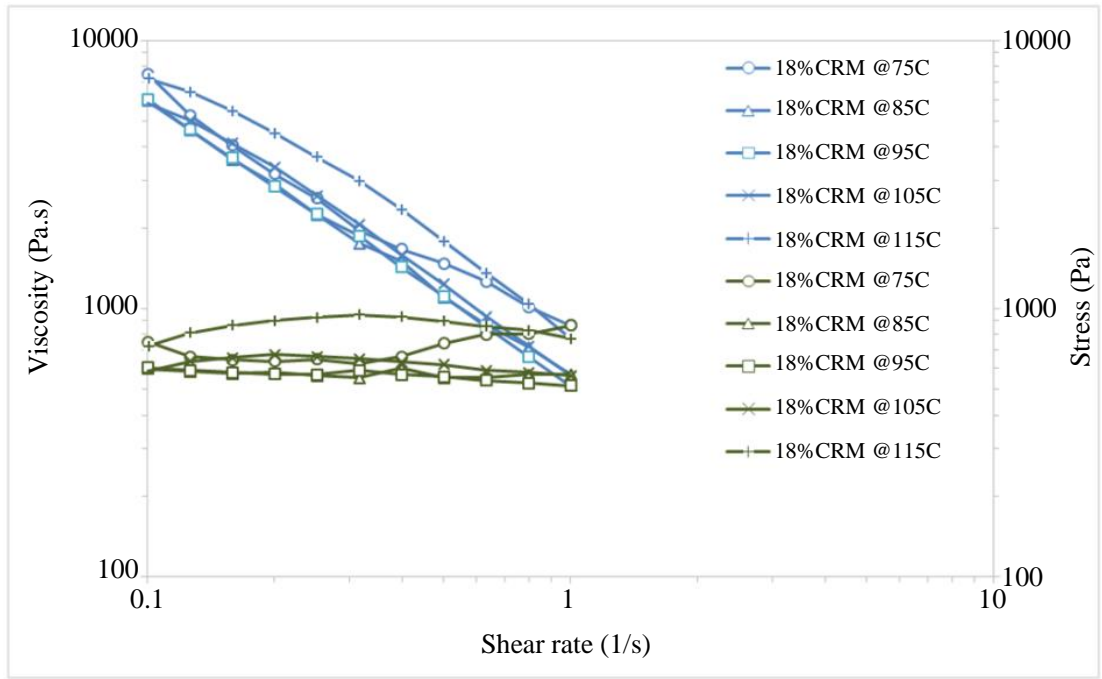

(d)

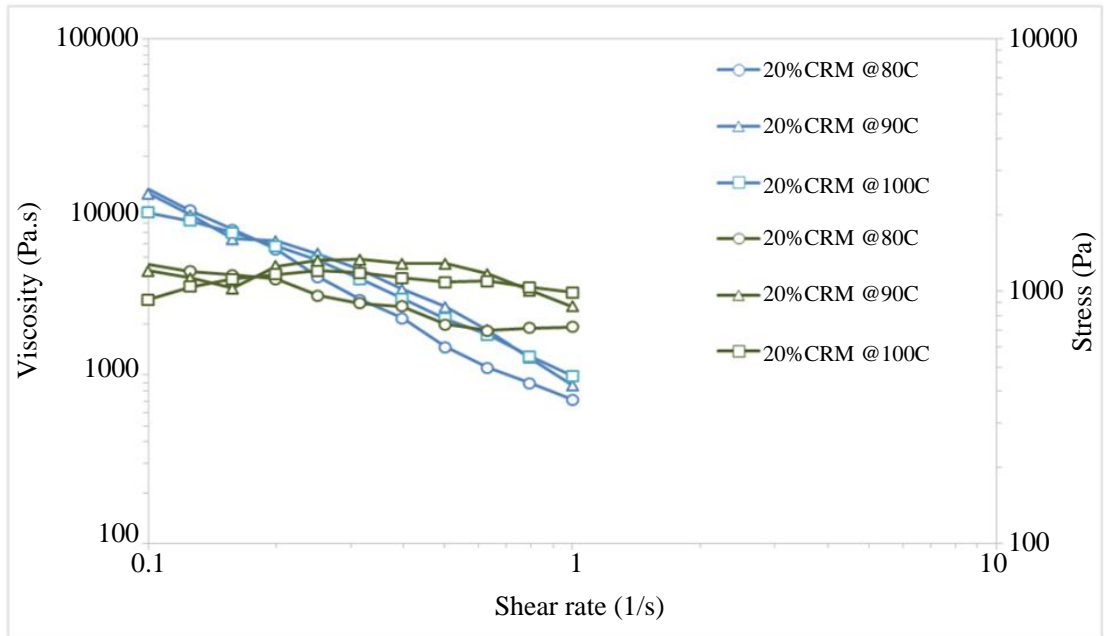

(e) 


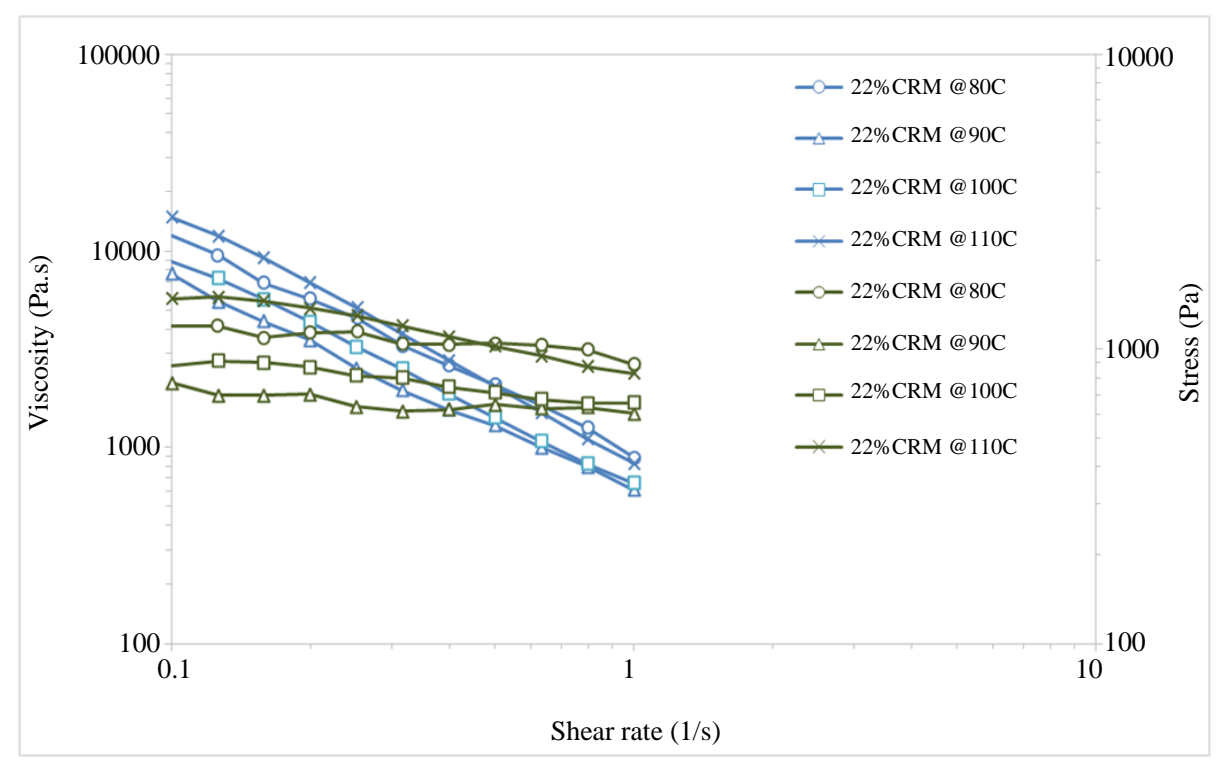

(f)

Fig. 5: Viscosity test results: (a) Pure (Neat Binder); (b) CRM Binder 15\% Rubber; (c) CRM Binder 17\% Rubber; (d) CRM Binder 18\% Rubber; (e) CRM Binder 20\% Rubber; (f) CRM Binder 22\% Rubber

\section{Flash Point Test}

Based on the results from this test, there is no concern and fire risk in using asphalt rubber in hot climates since all the tested CRM bitumen met the requirements of this test.

\section{Ductility Test}

Although CRM bitumen should be more ductile due to their rubber content (which increases viscosity and resilience of bitumen) the results herein suggested the opposite. Based on the following points, it has been determined that there are no concerns regarding ductility and aging of CRM bitumen (Tabatabaee et al., 2013).

There is no agreement among experts regarding the value of ductility test results in terms of defining pavement performance, with many studies failing to find any reliable trend for the relationship between ductility and pavement performance.

Detailed analysis of ductility test indicated that one of the fundamental problems with this test is the variation of sample geometry during the elongation. This confounding effect can cause significant problems leading to erroneous evaluation.

Specialized testing in Direct Shear Reheometer was designed to measure true ductility while carefully controlling the geometry of the samples. The results showed that modified binders are more ductile than conventional binders.

It is highly recommended that the ductility test be removed from modified binder specifications.

\section{Rolling Thin Film Oven}

The mass loss results from this test were found to be $0.0235 \%$ for CRM bitumen with $17 \%$ of rubber while $0.063 \%$ for control bitumen. According to these results, CRM bitumen is more durable than control bitumen.

\section{Marshall Test}

The results of the Marshall test are shown in the Tables 5a, 5b, 6a and 6b. As shown in Fig. 6, the percentage of CRM binder corresponding to $4 \%$ air voids was $5.3 \%$ in Asphalt Rubber Design No.1. Initially, it was chosen to be the optimum CRM binder content for this mix. Then, other properties corresponding to this binder content were checked (Fig. 6 to Fig. 11).

According to the results obtained from this mix, asphalt rubber with 5.3\% CRM binder met all the requirements of the Marshall mix design. CRM binder content corresponding to $4 \%$ air did not meet the requirement of VMA. It was below 13\% (minimum VMA corresponding to $4 \%$ air voids). Therefore, other CRM binder contents were checked. It was found that $4.8 \%$ could be the best option, since it met all the requirements. Thus, it has been chosen to be the reference content for this mix.

Furthermore, based on Fig. 6 the percentage of control binder corresponding to $4 \%$ air voids was $3.8 \%$ in conventional asphalt design No. 1. Since it was out of the binder content range as per the General Specifications for Kuwait Roadways and Highways, it has been eliminated for the selection of the optimum mix 
design. Therefore, other binder contents were evaluated to see the best one in meeting the requirements of Marshall mix design criteria based on Fig. 6 to 11.

Accordingly, $4.1 \%$ control binder was chosen as the optimum for this mix since it was the best amongst all other binder contents of conventional asphalt. However, not all properties corresponding to this binder met the requirements. Voids in Mineral Aggregate (VMA) was less than the requirement. This means the voids were not sufficient to accommodate the volume of binder that could provide adequate adhesion between aggregate particles. Also, flow was more than the limit, so rutting is likely to happen with conventional asphalt.

In mix design No. 2, it was found that $4.1 \%$ binder content could be the most viable option, since it met all the mix design criteria except for VMA.

Table 5a: Mix design No.1: Asphalt Rubber (AR) vs. Conventional Asphalt (CA)

\begin{tabular}{|c|c|c|c|c|c|c|c|c|c|c|}
\hline \multirow[b]{2}{*}{ Binder } & \multicolumn{2}{|c|}{ Unit Wt. $\left(\mathrm{kN} / \mathrm{m}^{3}\right)$} & \multicolumn{2}{|c|}{$\begin{array}{l}\text { Specific gravity of } \\
\text { paving mixture }\end{array}$} & \multicolumn{2}{|c|}{$\mathrm{V}_{\mathrm{a}}(\%)$} & \multicolumn{2}{|c|}{$\operatorname{VMA}(\%)$} & \multicolumn{2}{|c|}{ VFA $(\%)$} \\
\hline & $\mathrm{AR}$ & $\mathrm{CA}$ & $\mathrm{AR}$ & $\mathrm{CA}$ & AR & CA & $\mathrm{AR}$ & $\mathrm{CA}$ & AR & $\mathrm{CA}$ \\
\hline $3.5 \%$ & 23.071 & 23.905 & 2.556 & 2.552 & 7.976 & 4.503 & 14.066 & 10.961 & 43.296 & 58.915 \\
\hline $4 \%$ & 22.953 & 23.956 & 2.537 & 2.533 & 7.789 & 3.592 & 14.951 & 11.235 & 47.902 & 68.028 \\
\hline $4.5 \%$ & 23.005 & 24.035 & 2.519 & 2.514 & 6.919 & 2.560 & 15.202 & 11.405 & 54.486 & 77.553 \\
\hline $5 \%$ & 23.433 & 24.007 & 2.502 & 2.496 & 4.512 & 1.964 & 14.075 & 11.973 & 67.943 & 83.597 \\
\hline $5.5 \%$ & 23.611 & 23.932 & 2.484 & 2.478 & 3.108 & 1.561 & 13.879 & 12.710 & 13.879 & 87.714 \\
\hline
\end{tabular}

Table 5b: Mix design No.1: Asphalt Rubber (AR) Vs. Conventional Asphalt (CA)

\begin{tabular}{|c|c|c|c|c|c|c|c|}
\hline \multirow[b]{2}{*}{ Binder } & \multirow[b]{2}{*}{ Specimen No. } & \multicolumn{2}{|c|}{ Bulk specific gravity } & \multicolumn{2}{|c|}{ Factored marshall stability $(\mathrm{N})$} & \multicolumn{2}{|c|}{ Marshall flow $(0.25 \mathrm{~mm})$} \\
\hline & & $\mathrm{AR}$ & $\mathrm{CA}$ & $\mathrm{AR}$ & $\mathrm{CA}$ & $\mathrm{AR}$ & $\mathrm{CA}$ \\
\hline \multirow[t]{4}{*}{$3.5 \%$} & 1 & 2.317 & 2.445 & 15685.0 & 13187.5 & 13.272 & 14.676 \\
\hline & 2 & 2.426 & 2.438 & 20108.0 & 14255.6 & 09.644 & 13.148 \\
\hline & 3 & 2.313 & 2.427 & 13900.0 & 12700.4 & 11.608 & 13.432 \\
\hline & average & 2.352 & 2.437 & 16564.0 & 13381.0 & 11.510 & 13.750 \\
\hline \multirow[t]{4}{*}{$4 \%$} & 1 & 2.336 & 2.435 & 17041.0 & 11949.7 & 10.464 & 14.796 \\
\hline & 2 & 2.337 & 2.433 & 15041.0 & 12946.6 & 06.980 & 14.228 \\
\hline & 3 & 2.346 & 2.457 & 17886.0 & 12523.5 & 09.264 & 13.744 \\
\hline & average & 2.340 & 2.442 & 16656.0 & 12473.0 & 08.900 & 14.26 \\
\hline \multirow[t]{4}{*}{$4.5 \%$} & 1 & 2.334 & 2.449 & 13671.0 & 10751.2 & 10.424 & 15.012 \\
\hline & 2 & 2.358 & 2.454 & 14721.0 & 10172.7 & 10.736 & 15.148 \\
\hline & 3 & 2.343 & 2.448 & 14561.0 & 10938.2 & 10.240 & 12.904 \\
\hline & average & 2.345 & 2.450 & 14318.0 & 10621.0 & 10.470 & 14.350 \\
\hline \multirow[t]{4}{*}{$5 \%$} & 1 & 2.383 & 2.450 & 15422.7 & 10227.7 & 14.196 & 17.628 \\
\hline & 2 & 2.399 & 2.443 & 13980.4 & 08969.2 & 12.212 & 17.012 \\
\hline & 3 & 2.384 & 2.448 & 14989.4 & 09022.3 & 11.648 & 14.304 \\
\hline & average & 2.389 & 2.447 & 14798.0 & 9406.0 & 12.690 & 16.310 \\
\hline \multirow[t]{4}{*}{$5.5 \%$} & 1 & 2.408 & 2.429 & 14916.8 & 07760.6 & 12.748 & 24.26 \\
\hline & 2 & 2.415 & 2.444 & 15579.4 & 09317.7 & 12.796 & 18.936 \\
\hline & 3 & 2.397 & 2.446 & 13486.8 & 07934.1 & 11.484 & 20.200 \\
\hline & average & 2.407 & 2.440 & 14661.0 & 08337.0 & 12.340 & 21.130 \\
\hline
\end{tabular}

Table 6a: Mix Design No.2: Asphalt Rubber (AR) vs. Conventional Asphalt (CA)

\begin{tabular}{|c|c|c|c|c|c|c|c|c|c|c|}
\hline \multirow[b]{2}{*}{ Binder } & \multicolumn{2}{|c|}{ Unit Wt. $\left(\mathrm{kN} / \mathrm{m}^{3}\right)$} & \multicolumn{2}{|c|}{$\begin{array}{l}\text { Specific gravity of } \\
\text { paving mixture }\end{array}$} & \multicolumn{2}{|c|}{$\mathrm{V}_{\mathrm{a}}(\%)$} & \multicolumn{2}{|c|}{ VMA (\%) } & \multicolumn{2}{|c|}{ VFA $(\%)$} \\
\hline & AR & CA & $\mathrm{AR}$ & CA & $\mathrm{AR}$ & $\mathrm{CA}$ & $\mathrm{AR}$ & $\mathrm{CA}$ & $\mathrm{AR}$ & CA \\
\hline $3.5 \%$ & 23.626 & 23.862 & 2.560 & 2.556 & 5.929 & 4.843 & 12.000 & 11.121 & 50.589 & 56.455 \\
\hline $4 \%$ & 23.691 & 24.169 & 2.542 & 2.537 & 4.991 & 2.901 & 12.217 & 10.444 & 59.148 & 72.220 \\
\hline $4.5 \%$ & 23.553 & 24.119 & 2.524 & 2.519 & 4.863 & 2.386 & 13.180 & 11.094 & 63.103 & 78.496 \\
\hline $5 \%$ & 23.768 & 24.119 & 2.506 & 2.500 & 3.310 & 1.673 & 12.846 & 11.562 & 74.232 & 85.529 \\
\hline $5.5 \%$ & 24.024 & 24.194 & 2.488 & 2.482 & 1.580 & 0.650 & 12.374 & 11.754 & 87.229 & 94.467 \\
\hline
\end{tabular}


Sayed Mohamad Soleimani et al. / American Journal of Engineering and Applied Sciences 2020, 13 (2): 237.253 DOI: 10.3844/ajeassp.2020.237.253

Table 6b: Mix design No.2: Asphalt Rubber (AR) vs. Conventional Asphalt (CA)

\begin{tabular}{|c|c|c|c|c|c|c|c|}
\hline \multirow[b]{2}{*}{ Binder } & \multirow[b]{2}{*}{ Specimen No. } & \multicolumn{2}{|c|}{ Bulk Specific Gravity } & \multicolumn{2}{|c|}{ FactoredMarshallStability (N) } & \multicolumn{2}{|c|}{ MarshallFlow (0.25mm) } \\
\hline & & AR & $\mathrm{CA}$ & $\mathrm{AR}$ & CA & $\mathrm{AR}$ & CA \\
\hline \multirow[t]{4}{*}{$3.5 \%$} & 1 & 2.434 & 2.427 & 01152.6 & 10538.4 & 15.960 & 8.888 \\
\hline & 2 & 2.404 & 2.427 & 09609.7 & 11463.7 & 16.112 & 9.312 \\
\hline & 3 & 2.387 & 2.443 & 08901.1 & 13503.9 & 12.892 & 9.892 \\
\hline & average & 2.408 & 2.432 & 06554.0 & 11835.0 & 14.990 & 9.360 \\
\hline \multirow[t]{4}{*}{$4 \%$} & 1 & 2.424 & 2.468 & 10223.1 & 11633.5 & 10.592 & 11.212 \\
\hline & 2 & 2.424 & 2.462 & 10224.0 & 11285.0 & 10.164 & 9.084 \\
\hline & 3 & 2.397 & 2.462 & 06916.8 & 11239.9 & 12.444 & 11.804 \\
\hline & average & 2.415 & 2.464 & 09121.0 & 11386.0 & 11.070 & 10.700 \\
\hline \multirow[t]{4}{*}{$4.5 \%$} & 1 & 2.381 & 2.452 & 06965.7 & 10506.8 & 13.060 & 11.948 \\
\hline & 2 & 2.409 & 2.462 & 08771.1 & 09542.7 & 11.520 & 11.544 \\
\hline & 3 & 2.413 & 2.462 & 09017.5 & 11405.3 & 11.576 & 13.708 \\
\hline & average & 2.401 & 2.459 & 08251.0 & 10485.0 & 12.050 & 12.400 \\
\hline \multirow[t]{4}{*}{$5 \%$} & 1 & 2.410 & 2.457 & 08639.2 & 08806.4 & 12.348 & 19.628 \\
\hline & 2 & 2.423 & 2.456 & 09446.9 & 10584.3 & 13.292 & 13.468 \\
\hline & 3 & 2.436 & 2.462 & 10035.3 & 09362.6 & 18.116 & 15.412 \\
\hline & average & 2.423 & 2.459 & 09374.0 & 09584.0 & 14.590 & 16.170 \\
\hline \multirow[t]{4}{*}{$5.5 \%$} & 1 & 2.447 & 2.453 & 10750.6 & 08275.4 & 16.136 & 19.716 \\
\hline & 2 & 2.447 & 2.457 & 11723.9 & 08876.5 & 17.012 & 16.132 \\
\hline & 3 & 2.453 & 2.488 & 11595.0 & 09012.2 & 15.676 & 17.884 \\
\hline & average & 2.449 & 2.466 & 11357.0 & 08721.0 & 16.270 & 17.910 \\
\hline
\end{tabular}

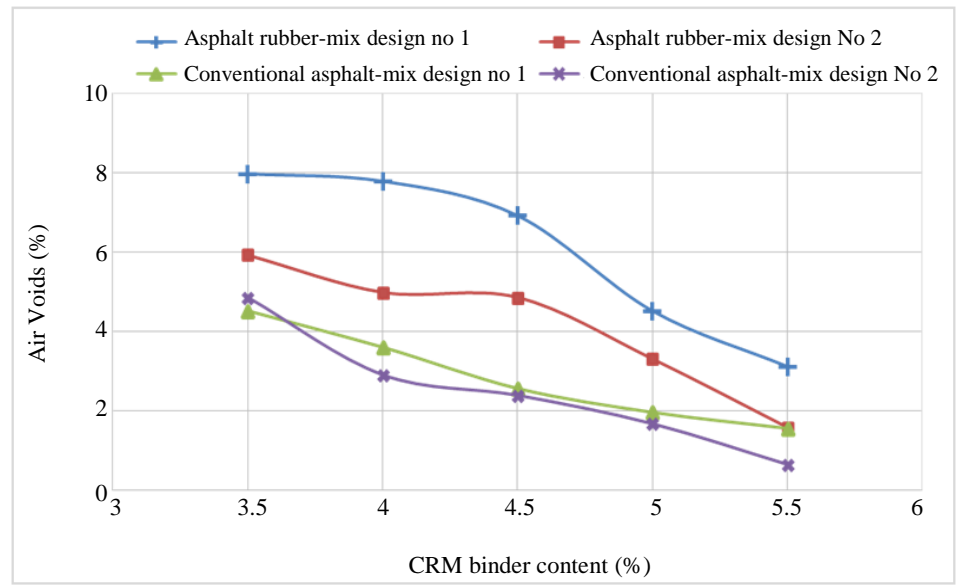

Fig. 6: Air voids vs. CRM binder content

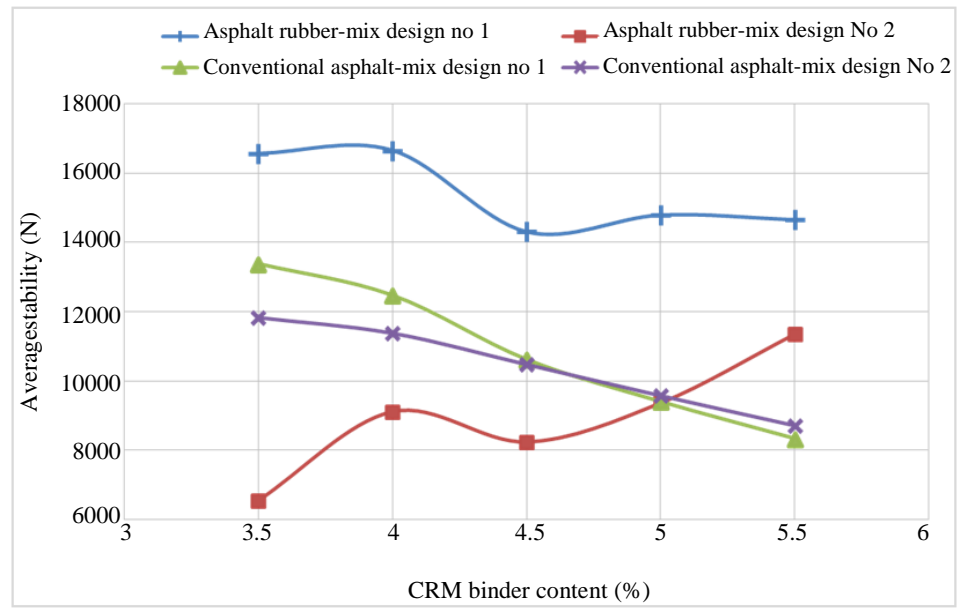

Fig. 7: Stability vs. CRM binder content 


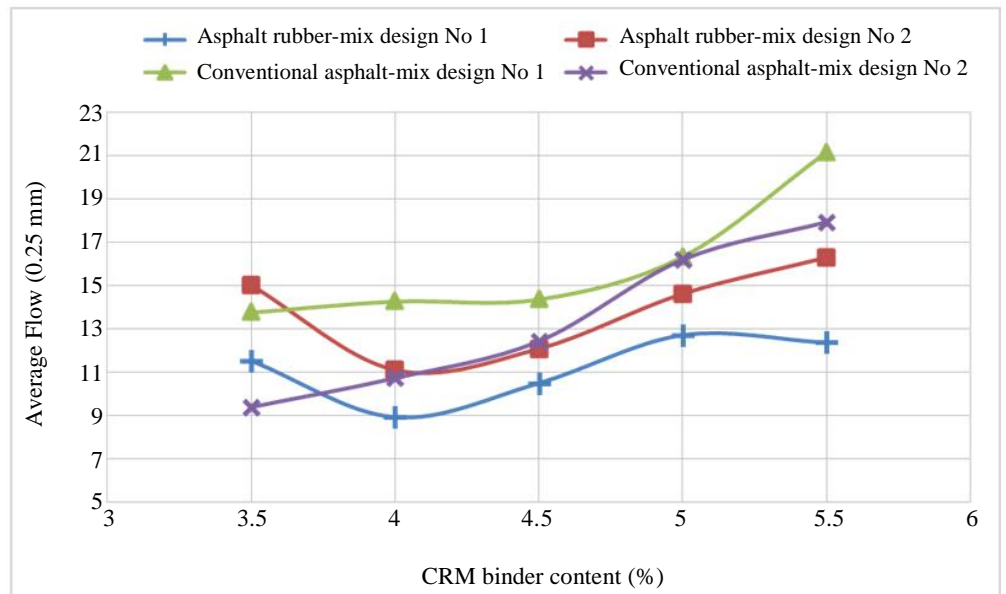

Fig. 8: Unit Weight vs. CRM Binder Content

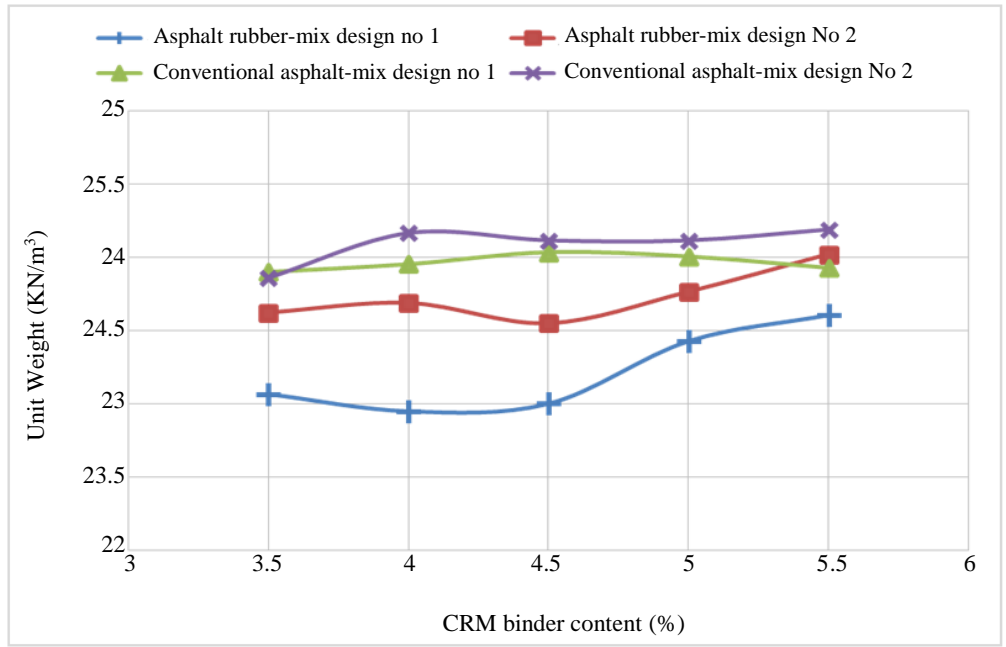

Fig. 9: Average Flow vs. CRM Binder Content

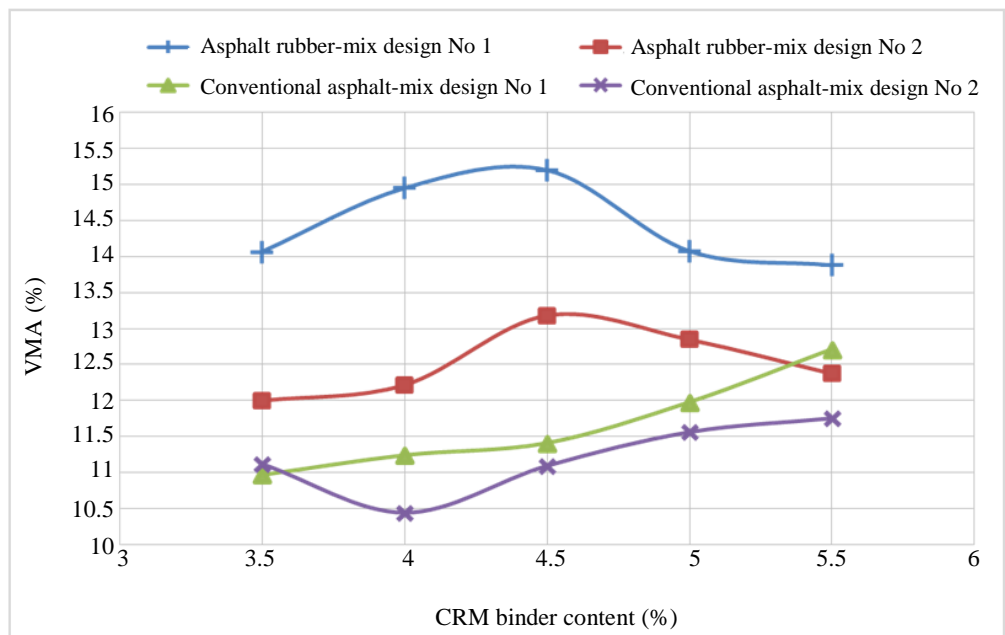

Fig. 10: VMA vs. CRM binder content 
According to the results obtained from the two mix designs both asphalt rubber and conventional asphalt, as shown in Table 7, it has been found that Asphalt Rubber (AR) would be better than Conventional Asphalt (CA). However, AR in mix design No.1 provided significant improvements in stability and resistance to deformation. Thus, mix design No.1 was chosen to be the optimum mix design in this study.

The chosen percentage of binder content will provide more than $2 \%$ air voids (as the low amount of air voids may break the aggregate skeleton during the compaction).

\section{Characterization of Mixtures}

After finding the optimum binder content for both asphalt rubber and conventional asphalt, three main tests were used to characterize the behaviour of these mixtures to evaluate their performance in terms of rutting, shear resistance and moisture susceptibility. These tests were as follows.

\section{Immersion Marshall Test}

The minimum allowable retained stability of immersed asphalt specimens is $75 \%$ (Ismanto et al., 2005). Based on results shown in Table 8 , the retained stability of asphalt rubber was much larger than the minimum, while conventional asphalt was less than the requirement. This means asphalt rubber is better in resistance to moisture damage than conventional asphalt.

\section{Indirect Tensile Test}

Based on the recommended maximum high temperature indirect tensile strength requirements, it was found that both asphalt rubber and conventional asphalt met the requirements as shown in Table 9.

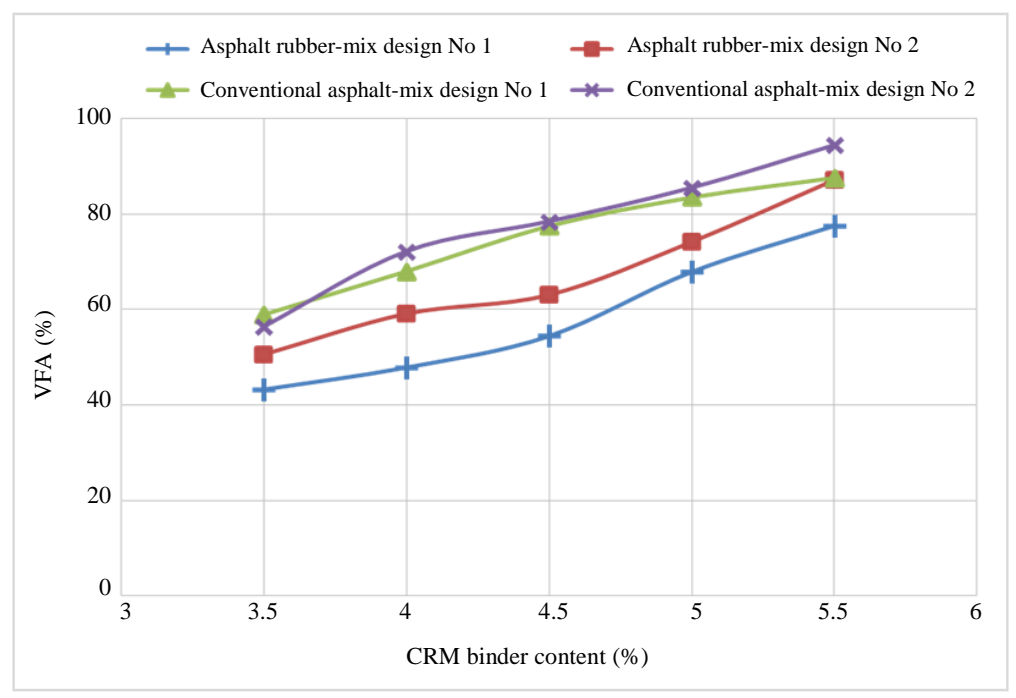

Fig. 11: VFA vs. CRM binder content

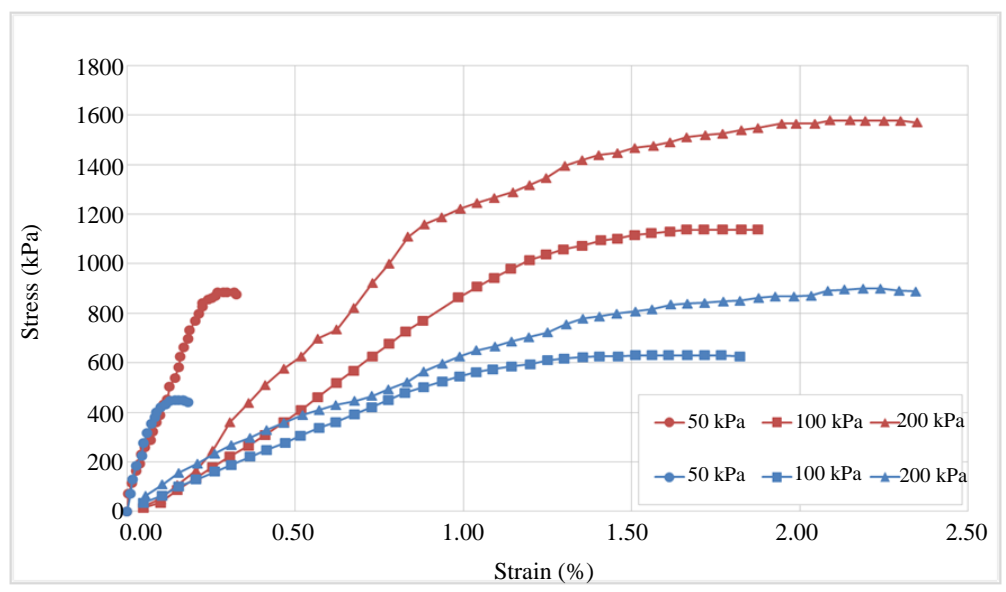

Fig. 12: Stress-strain curve of asphalt rubber and conventional asphalt 
Table 7: The properties of optimum asphalt mixes and the specification requirements

\begin{tabular}{llllll}
\hline Properties & AR Mix No.1 & AR Mix No.2 & CA Mix No. 1. CAMix No.2 & Specifications Requirements \\
\hline Factored marshall stability (N) & 1480 & 9500 & 1180 & 1100 & Min.:8000 \\
Marshall flow (0.25mm) & 12.0 & 14.0 & 14.5 & 11.8 & $8-14$ \\
VMA (\%) & 14.3 & 12.6 & 11.4 & 11.1 & Min.:12.5 corresponding to 3.5\% Va \\
VFA (\%) & 74 & 71 & 70 & 71 & $65-75$ \\
\hline
\end{tabular}

Table 8: Index of retained stability of asphalt rubber and conventional asphalt

\begin{tabular}{lll}
\hline Retained stability & $\begin{array}{l}\text { Asphalt rubber } \\
(5.3 \% \text { CRM })\end{array}$ & $\begin{array}{l}\text { Conventional asphalt } \\
(4.1 \% \text { Control })\end{array}$ \\
\hline Stability in dry conditioned, $S_{d},(\mathrm{~N})$ & 9247 & 11900 \\
Stability in moisture conditioned, $S_{m},(\mathrm{~N})$ & 9031 & 8150 \\
Stability ratio, $S_{d} / S_{m} * 100(\%)$ & 97.7 & 68.5 \\
\hline
\end{tabular}

Table 9: Indirect tensile strength of asphalt rubber and conventional asphalt

\begin{tabular}{|c|c|c|c|c|}
\hline Properties & \multicolumn{3}{|c|}{ Asphalt rubber (5.3\% CRM) } & Conventional asphalt (4.1\% Control) \\
\hline Specimen diameter $(\mathrm{mm})$ & 101.46 & 101.4 & 101.54 & 101.26 \\
\hline Specimen height (mm) & 65.02 & 64.97 & 64.88 & 61.85 \\
\hline Load $(\mathrm{N})$ & 11125 & 10487 & 11752 & 11899.7 \\
\hline IDT tensile strength $(\mathrm{kPa})$ & 1073.6 & 1035.8 & 1135.8 & 1209.5 \\
\hline Average IDT $(\mathrm{kPa})$ & 1074.3 & 1209.5 & & \\
\hline
\end{tabular}

\section{Triaxial Test}

In this test, three different lateral pressures $(50,100$ and $200 \mathrm{kPa}$ ) were applied on asphalt rubber and conventional asphalt. Based on these readings, triaxial software generated the stress-strain curve of the samples as shown in Fig. 12. According to these results, asphalt rubber could be better than conventional asphalt in terms of shear resistance, because it was observed to carry more axial and lateral loads before the failure point.

\section{Conclusion}

The main objective of this study was to characterize the properties and behaviour of dense graded asphalt mixtures containing crumb rubber as modifier. These properties were investigated using both binder and mixtures testing. The following conclusions were drawn from thin investigation:

- The addition of crumb rubber could increase the rheological properties of control binder since the viscosity is increased. The increased stiffness enhances the performance characteristics of bitumen in terms of better protection against increased traffic loads and adverse climate conditions

- Based on the American Society of Testing Materials standard (ASTM D6114/D6114M-19, 2019), type I asphalt rubber binder are generally recommended for use in hot climate areas which their average monthly ambient temperature is $43^{\circ} \mathrm{C}$ or greater. $17 \%$ of crumb rubber fulfilled the specifications of this type and showed significant enhancements of the control binder with less susceptibility to temperature and deformation

- Asphalt rubber could carry more traffic loads since the results from Marshall test showed that asphalt rubber mixes had higher stability values as compared to conventional mixes. In addition, they had less flow values which indicate better resistance to deformation and cracks

- The results from laboratory experiments in this research showed that asphalt rubber binder can enhance the performance of dense graded asphalt mixes. Thus, asphalt rubber can be used for main layers as well as for rehabilitation and surface treatment

Based on these conclusions, crumb rubber modified bitumen can be an ideal solution to optimize the performance of asphalt in road pavements. The outcome of this study would encourage the use of locally-sourced waste materials in the future production of asphalt on a country-wide scale, which will help reduce the generation of waste in the State of Kuwait and therefore bring it more in alignment with UN Sustainable Development Goals (SDGs), particularly SDG 11, which is to make our communities more inclusive, safe, resilient and sustainable.

\section{Acknowledgement}

The authors would like to acknowledge the help of Mr. Tahir Afrasiab in preparing the samples for this study. 


\section{Author's Contributions}

Sayed Mohamad Soleimani: Supervised the work carried out, collected, analyzed the results and reviewed the manuscript.

Alanoud Faheiman: Compiled the results and finalized the manuscript.

Zainab Mowaze: Prepared the samples, carried out the laboratory tests and prepared the first draft of the manuscript.

\section{Ethics}

The authors declare no ethical conflicts.

\section{References}

ADT, 2005. Section 413. Surface treatments and pavements. Arizona Department of Transportation ADOT, Arizona.

Arab Times, 2019. Arabtimes online. http://www.arabtimesonline.com/news/kd100mlnneeded-for-road-repairs/

Arun, M. and P. Ganesh, 2013. Laboratory evaluation of usage of waste tyre rubber in bituminous concrete. Int. J. Sci. Res. Public.

Asadi, S., N.S. Babu, B.K.H. Kumar and M. Sumanth, 2016. Crumb rubber utilization in pavements to improve the durability: An experimental study. Int. J. Applied Eng. Res., 11: 6418-6423.

Asphalt Academy, 2007. The use of modified bituminous bindersin road construction. Asphalt Academy, Pretoria.

Asphalt Academy, 2015. Technical guideline: The use of modified bituminous bindersin road construction. Southern African Bitumen Association.

Asphalt Institute, 1997. Mix Design Methods for Asphalt Concrete and Other Hot-Mix Types. 6th Edn., Asphalt Institute, pp: 141.

ASTMD113-17, 2017. Standard test method for ductility of asphalt materials. ASTM International, West Conshohocken, PA.

ASTM D2850-15, 2015. Standard test method for unconsolidated-undrained triaxial compression test on cohesive soils1. ASTM International, West Conshohocken, PA.

ASTM D4867/D4867M-09, 2009. Standard test method for effect of moisture on asphalt concrete paving mixtures. ASTM International, West Conshohocken, PA.

ASTM D5/D5M-13, 2013. Standard test method for penetration of bituminous materials. ASTM International, West Conshohocken, PA.

ASTM D6114/D6114M-19, 2019. Standard specification for asphalt-rubber binder. ASTM International, West Conshohocken, PA.
ASTM D6926-16, 2016. Standard practice for preparation of bituminous using marshall apparatus. ASTM International, West Conshohocken, PA.

ASTM D6931-17, 2017. Standard test method for Indirect Tensile (IDT) strength of asphalt mixtures1. ASTM International, West Conshohocken, PA.

CDT, 2003. Asphalt rubber usage guide. California Department of Transportation Sacramento, Folsom Boulevard.

Charles, J., R. Davison and C.J. Glover, 2000. A comprehensive laboratory and field study of highcure crumb-rubber modified asphalt materials. Texas Transportation Institute, Austin, Texas.

Deshmukh, N. and D. Kshirsagar, 2017. Utilization of rubber waste in construction of flexible pavement. Int. J. Adv. Res. Dev.

DMR, 2013. World's biggest tyre graveyard: Incredible images of Kuwaiti landfill site that is home to SEVEN MILLION wheels and so huge it can be seen from space. Daily Mail Reporter.

Emeny, J. and H. Seddik, 1997. Moisture damage of asphalt pavements and antistripping addittives. Transportation Association of Canada, Ottawa, Canada.

Franesqui, M.A., J. Yepes and C. García-González, 2019. Improvement of moisture damage resistance and permanent deformation performance of asphalt mixtures with marginal porous volcanic aggregates using crumb rubber modified bitumen. Construct. Build. Mater.., 201: 328-339.

DOI: 10.1016/j.conbuildmat.2018.12.181

Ghabchi, R., M. Zaman and A. Arshadi, 2016. Use of Ground tire rubber (Gtr) in asphalt pavements: Literature review and dot survey. Oklahoma Department of Environmental Quality.

Hamzah, M., H. Mohamed and H. Ismail, 2006. Laboratory investigation of the properties of a newly developed crumb rubber modified (cri1). Emirates J. Eng. Res., 11: 67-72.

Hicks, R. and J. Epps, 2018. Life cycle costs for asphaltrubber paving materials. Oregon State University, Oregon, United States.

Huang, B., L.N. Mohammad and P.S. Graves, 2002. Louisiana experience with crumb rubber-modified hot-mix asphalt pavement. Trans. Res. Record, 1789: 1-13. DOI: $10.3141 / 1789-01$

Ismanto, B., K. Ginting and T. Liliani, 2005. Workability and resilient modulus of asphalt concrete. J. Eastern Asia Society Trans. Stud., 6: 1302-1312.

Kaloush, K., K. Biligiri, M. Rodezno, M. Souliman and J. Reed, 2010. Laboratory evaluation of rubber and polymer modified bituminous mixtures constructed in Stockholm. Final Report, Swedish Transport Administration, Vägverket. 
Kaloush, K.E., 2014. Asphalt rubber: Performance tests and pavement design issues. Constr. Buil. Mater., 67: 258-264.DOI: 10.1016/j.conbuildmat.2014.03.020

Khosla, N. and K. Harikrishnan, 2005. Tensile strength-a design and evaluation tool for superpave. North Carolina State University, Raleigh, North Carolina, United States.

Kok, B.V. and N. Kuloglu, 2007. The effects of different binders on mechanical properties of hot mix asphalt. Int. J. Sci. Technol., 2: 41-48.

Mang, T., 2003. Bituminous materials and mixtures. In J. R. W.f. CHEN, The Civil Engineering Handbook. CRC Press.

Mashaan, N., A. Ali, M. Karim and M. Abdel, 2014. A review on using crumb rubber in reinforcement of asphalt pavement. Sci. World J.

Mathew, T. and K. Krishna Rao, 2006. Pavement materials: Bitumen', Introduction to Transportation Engineering.

Michael, S. and P. John, 2011. Materials for Civil and Construction Engineers. 3rd Edn., Pearson, ISBN-10: 0138009562, pp: 600.

Mohammad, L.N., B. Huang, F.L. Roberts and M. Rasoulian, 2019. Accelerated loading performance and laboratory characterization of crumb rubber asphalt pavement. Road Mater. Pavement Design, 1: 467-493. DOI: $10.1080 / 14680629.2000 .12067156$

Moses, T., J. Hulsey and B. Connor, 2009. Airport manager's guide for the maintenance of asphalt pavements of, Fairbanks. University of Alaska, Alaska.

MPW, 2012. General specifications for Kuwait roads. Ministry of Public Works, Kuwait.

Saberi F., M. Fakhri and A. Azami, 2017. Evaluation of warm mix asphalt mixtures containing reclaimed asphalt pavement and crumb rubber. J. Cleaner Product., 165: 1125-1132.

DOI: 10.1016/j.jclepro.2017.07.079
Said, S., H. Carlsson, L. Viman and T. Nordgren, 2015. Performance of asphalt rubber pavements. Proceedings of the Rubberized Asphalt Rubber Conference, (ARC' 15), Las Vegas, USA.

Scofield, L., 1989. The history, development and performance of asphalt-rubber at Adot: Special report. Phoenix, Ariz: Arizona Department of Transportation. United States. Federal Highway Administration., Arizona. Department of Transportation., Arizona Transportation Research Center., ADOT-RPA_A1211, AZ-SP-8902.

Shuler, S., 2014. Use of waste tires (Crumb Rubber) on colorado highways. Report No. Cdot-2014-12.

Tabatabaee, H., C. Clopotel, A. Arshadi and H. Bahia, 2013. Critical problems with using the asphalt ductility test as a performance index for modified binders. J. Trans. Res. Board, 2370: 84-91.

DOI: $10.3141 / 2370-11$

Tahmoressi, M., 2001. Evaluation of asphalt rubber pavement in Texas. Rubber Pavement Association, Report Tempe, Arizona.

Venudharan, V., K.P. Biligiri and J.B. Sousa, 2016. Asphalt-rubber gap-graded mixture design practices: A state-of-the-art research review and future perspective. Road Mater. Pavement Design, 18: 730-752. DOI: 10.1080/14680629.2016.1182060

Wang, H., Z. Dang, L. Li and Z. You, 2013. Analysis on fatigue crack growth laws for Crumb Rubber Modified (CRM) asphalt mixture. Constr. Buil. Mater., 47: 1342-1349.

Way, G., K. Kaloush and K. Biligiri, 2012. AsphaltRubber Standard Practice Guide. 2nd Edn., Rubber Pavement Association.

Zhou, H., S. Holikatti and P. Vacura, 2014. Caltrans use of scrap tires in asphalt rubber products: A comprehensive review. J. Traffic Trans. Eng., 1: 39-48. DOI: 10.1016/S2095-7564(15)30087-8 